\title{
Administrative Crisis: The Role of Effective Leadership Styles in Crisis Management
}

\author{
Bayad Jamal Ali ${ }^{1}$, Govand Anwar ${ }^{2}$
}

\begin{abstract}
${ }^{1}$ Business Administration Department, Komar University of Science and Technology, Sulaimani 46001, Kurdistan Region - Iraq ${ }^{2}$ Department of Business Administration, College of Administration and Financial Sciences, Knowledge University, 44001 Erbil, Kurdistan Region, Iraq
\end{abstract}

Received: 09 Apr 2021; Received in revised form: 07 May 2021; Accepted: 29 May 2021; Available online: 06 Jun 2021

\begin{abstract}
The current study's major goal is to look into the relationship between leadership styles and crisis management at Erbil's Ministry of Planning. A quantitative methodology was employed to pursue the goals of this study. A total of 630 people took part in the survey. The data show that charismatic leadership had the highest value of all leadership types. The study concluded that charismatic leadership has become more rigorous in recent decades, and that organizations' growth strategies frequently require modification during times of crisis. The current study's findings will serve as a guide for government organizations, particularly Erbil's Ministry of Planning, in identifying individuals who are capable of leading in a charismatic manner during times of crisis.
\end{abstract}

Keywords - Charismatic Leadership, Transformational Leadership, Transactional Leadership, Crisis Management, Iraq.

\section{INTRODUCTION}

The importance of a leader's aptitude and talent is in managing crises and transitioning from a current financial condition (Abdullah et al. 2021) and a society based on logic and linearity to a financial position and a society based on inventiveness and creativity (Ahmed et al. 2021). Government officials, managers, and leaders of corporate firms and huge organizations make critical decisions on a regular basis and anticipate favorable results (Ahmed et al. 2021)in attaining their goals (Akoi et al. 2021). Continually, decisions are made to issue an order, fix a problem, handle a crisis (Ali \& Anwar, 2021), or deal with several unsatisfactory outcomes (Ali et al. 2021). The most essential thing is to make the best decision possible, one that is well-understood by all parties (Ali et al. 2021)involved and leads in positive outcomes. Leadership is related to making the proper decision (Ali et al. 2021). As a result, in order to deal with or handle any problem or crisis (Ali, 2014), it is strongly recommended to manage less and lead more (Ali, 2016). The focus of this research is on leadership styles and their link to crisis management (Ali, 2020). Leaders frequently regard this as a source of inspiration for their people. Leadership has a critical role in ensuring that This article can be downloaded from here: www.ijaems.com effective performance is maintained. For example (Ali, 2021), followers who are aware of the link between the firm's performance and the firm's or organization's objectives and values increase their efforts in positively contributing to the firm's or organization's aims (Ali, et al. 2021). Leadership has a crucial influence in shaping an organization's culture (Andavar et al. 2020). Organizational culture is typically articulated by leaders who create values, promote proper member behavior (Anwar \& Abd Zebari, 2015), and reinforce punishment and rewards (Anwar \& Abdullah, 2021). On the other hand, in today's world, organizations seek to form a team as their first step in overcoming crises that may cause future damage to the organization (Anwar \& Balcioglu, 2016). Many past academic academics have undertaken study in the subject of leadership that distinguishes the leadership idea from the management idea (Anwar \& Climis, 2017), as well as their successes in achieving achieved outcomes and efficiency in the organization (Anwar \& Ghafoor,2017). Several academics and researchers have sought to offer the accurate classification and description of their vital tasks and responsibilities by relying on a variety of organizational behavior perception and theories and translating them to the 
actual leading duties and activities (Anwar \& Qadir, 2017). Organizational Behavior investigates leadership styles and managers based on their personality and characteristics (Anwar \& Shukur, 2015), and assists in responding to diversification, economic force, enhanced labor abilities (Anwar \& Surarchith, 2015), work-life balance, improved customer service, and the creation of an ethical workplace environment (Anwar, 2016). OB focuses on how managers may improve efficiency and effectiveness (Anwar, 2017), raise employee commitment (Anwar, 2017), decrease turnover within the organization, raise employee satisfaction, and boost customer satisfaction. Additionally, $\mathrm{OB}$ provides and demonstrates the direction and plan for leaders, particularly managers, to select the suitable and relevant styles that best meet the organization's values in order to achieve corporate goals and personal objectives (Anwar, K., \& Louis, 2017). As a result (Aziz et al. 2021), it is accurate to declare that it is a perspective that an investigation of the effects an individual labor and group of labors, as well as the organizational chart (Demir et al. 2020), have on internal behavior that corresponds to their goals to achieve a healthy and ethical environment. Firms are looking for leaders with a clear vision to inspire their followers while also possessing the transformational leadership qualities and charisma necessary to set and sell their vision to their followers (Faraj et al. 2021). Furthermore (Hameed \& Anwar, 2018), a leader's actual performance might be a result of displaying the appropriate behaviors; several authors and academicians have noted that employees may have a pretty consistent or standardized understanding of the leader's behavior or vision (Hamza et al. 2021). One of the most important goals in the construction of public sectors is to maximize profit and raise its market value; while the public sector achieves this goal on one hand (Ismael et al. 2021), it also contributes to the country's progress and civilization's prosperity on the other (Jamal et al. 2021). However, the public sector, which operates in an environment of risk and uncertainty, may face difficulties from time to time (Sabir et al. 2021). These challenges that the public sector faces could stem from within its own structures as well as from the country's overall economic situations (Saleh et al. 2021). Because of the growth in the frequency of occurrence of leadership and crisis (Sorguli et al. 2021), as well as the negative impacts on the public sector at various levels, this study looked into the notion of leadership and crisis in depth (Talim, et al. 2021). The environment in which government agencies operate is always changing, exposing them to a variety of threats (Top \& Ali, 2021). The chances of the public sector surviving if it is unable to identify timely and proper solutions to such threats, lacks the ability to fix problems as they arise, and is unable to take the required steps to avoid recurrence of previously handled problems are dwindling. Being prepared for crises is the only way to get rid of them without causing damage, or at the very least with the least amount of damage feasible (Anwar \& Abd Zebari, 2015). This, in turn, needs the presence of early warning systems within public sector institutions that are capable of detecting crisis signals prior to the occurrence of the aforementioned crises (Anwar \& Abdullah, 2021). The environmental activities to overcome any hazards that may influence a person, enterprises, or organizations are referred to as crisis management (Anwar \& Balcioglu, 2016). Crisis management has unquestionably emerged as a new management principle (Anwar \& Climis, 2017). The role of crisis management is to advise managers in dealing with uncertain and unpredictable events that occur inside the business, and to assist them in developing a better plan for increasing productivity and achieving high performance quality (Anwar \& Ghafoor,2017). Furthermore, according to (Anwar \& Qadir, 2017), crisis management is the process by which a company handles a major event that threatens to harm the company, its partners, or the general public (Anwar \& Shukur, 2015). The government should find the best suitable leader who fits the current situation in order to manage the crisis, or leaders should be able to change their current leadership styles or leadership characteristics to the best match with the current situation, according to this study (Anwar \& Surarchith, 2015). If the leaders of Kurdistan failed to address and solve the current financial crisis, the government should find the best suitable leader who fits the current situation in order to manage the crisis, according to this study (Anwar, 2016). This research looked at three different leadership styles: transformational leadership, transactional leadership, and charismatic leadership (Anwar, 2017).

\section{LITERATURE REVIEW}

Leadership, according to (Anwar, 2017), refers to a person's ability to influence the remainder of a group of individuals in order to achieve a goal or set of goals. As a result, leadership is about duplicating with change and vision creation for motivating individuals (Anwar, K., \& Louis, 2017). It is also about the talents and competences that a leader exhibits to influence a group of people to achieve a vision or a created set of targets (Aziz et al. 2021). Furthermore, as discussed by (Hameed \& Anwar, 2018) (Hameed \& Anwar, 2018), it is critical to note that leadership is viewed as a social growth, as well as the importance of recognizing how an individual acts and fees. According to (Ali et al. 2021), it entails demonstrating the path that will drive people to work joyfully by fostering harmony in the pursuit of a common objective. It is true to 
say that the efficacy of leadership within a company is determined by how individuals perform and act in terms of achieving objectives successfully (Ali, et al. 2021), and for this reason, successful leaders are those who are able to create value by choosing the greatest fit for the scenario (Jong, et al., 2016). Meanwhile, a successful leadership style focuses on determining what the organization's future looks like, assisting in bringing individuals together with the leader's vision (Anwar, K., \& Louis, 2017), and influencing each individual to attain the corporate vision despite all obstacles (Anwar, 2017). Furthermore, according to the functional method, leadership is defined by four major actions: the ability to adapt to change, commitment to the company and organizational vision, determining the direction, and developing corporate mission (Anwar, 2016).

Researchers and many scholars have decided to establish definitions for a manager and management in order to find the best ways to present evidence for approaches to leadership effectiveness (Anwar \& Surarchith, 2015), argued that managers use authority to implement the vision and strategy provided by leaders, coordinates and staffs the organization, and deals with problems (Anwar \& Shukur, 2015). Some examples of leadership styles are as follows: According to (Anwar \& Qadir, 2017), transformational leadership is an important performance supplied by the leader to inspire the followers to desire the group's interest over individual interests, and the leader pays attention to the interests of their followers (Anwar \& Ghafoor,2017). Individuals are inspired by transformational leaders who show and direct them down the correct route, demonstrate each follower's responsibilities, and inspire them with good attitudes. According to (Anwar \& Climis, 2017), there is a favorable and significant relationship between transformational leadership and leader member exchange. The distinction between transactional and transformational leadership has been the subject of numerous previous studies. Individual growth is the goal of transformational leadership, which includes a leader who has an impact on an individual's issue by screening and examining prior concerns using current methods, as well as a leader who stimulates individuals with positive attitudes. The transactional leaders, according to (Anwar \& Balcioglu, 2016), direct individuals by explaining each individual's responsibilities and duties in order to achieve corporate goals. Furthermore, according to (Anwar \& Abdullah, 2021), transactional leadership assists individuals in determining and assigning obligations to each follower in order to achieve corporate goals (Anwar \& Abd Zebari, 2015).

According to (Anwar, K., \& Louis, 2017), transactional leaders develop objectives and targets in order to certify achievement; they communicate actions effectively, and align assets with employee collaboration to achieve the objectives, which ultimately motivates employees. Earlier studies (Anwar, 2017) and (Bass et al., 2003) demonstrated a substantial link between individual conduct and transactional leadership, as well as a favorable link between individual attitude and transactional leaders. Several recent studies (Anwar, 2016) have found a strong link between transactional leadership and OCB. Leaders who are transformative and transactional are not dissimilar; nonetheless, they are not equally important (Anwar \& Surarchith, 2015). Finally, charismatic leadership is defined by (Anwar \& Shukur, 2015)as a person who has an impact on followers through the employment of symbols, stories, and images in order to achieve amazing results. Charismatic leaders have a vision for their followers' future success. Furthermore, charismatic leaders are willing to put everything on the line to demonstrate their dedication. Previous research, such as (Anwar \& Qadir, 2017), has found a link between charismatic leadership and organizational success. Furthermore, both (Anwar \& Ghafoor,2017) and (Anwar \& Climis, 2017) have found a positive association between charismatic leadership and OCB. In addition, (Anwar \& Balcioglu, 2016) presented findings from other studies that validated the effects of charismatic leadership on OCB. Inspired followers under charismatic leadership can achieve positive results through determination, comprehensiveness, and identification with organizational objectives, according to (Anwar \& Abdullah, 2021). (Anwar \& Abd Zebari, 2015)identified empirical studies that confirmed the positive relationship between charismatic leadership and $\mathrm{OBC}$, as well as several studies that identified charismatic leader's characteristics. One of the studies mentioned four main charismatic leader's characteristics, the first of which is taking risks in order to achieve the vision, leaders are concerned about their followers' needs, and leaders are willing to take risks in order to achieve the vision (Andavar et al. 2020).

Crisis is an unplanned transformation process that threatens the entire organization's assets, goals, and resources, creates tension among members of the organization due to uncertainties and time pressure, and covers a limited time period for removing or minimizing the effects through necessary precautions. Crisis, according to (Anwar \& Abd Zebari, 2015), is a scenario in which the fundamental structures and conventions are impacted.

Unforeseen developments have had a negative impact. According to (Minh Ly-Le, 2015), the crisis is simply a significant condition of imbalance that has obliterated the public sector's normal operations. This phase is one that poses a threat to the organization's short and long-term goals, needs quick response while also limiting the decision-making period for the reaction, and most

This article can be downloaded from here: www.ijaems.com 
importantly, surprises decision-making units with its presence. In this sense, the crisis can be defined (Anwar \& Abdullah, 2021), as a situation that has reached a critical stage, transformations that require swift conformity, and the consequences and reflections of a disorganized and unplanned event on the entire public sector. According to (Anwar \& Balcioglu, 2016), a crisis is a tense condition that jeopardizes the top goals of public sectors, sometimes even jeopardizing their survival, and necessitates immediate action, as well as a condition in which prediction and preventative procedures are insufficient (Anwar \& Climis, 2017).

It is not a correct strategy, according to (Anwar \& Ghafoor,2017), to describe all poor conditions observed within organizations as crises. For example, a government leadership that forecasts next year's inflation to be significantly lower than this year's may face challenges, and this circumstance may be classified as a crisis. When considering a crisis as a leadership issue, all financial challenges that do not jeopardize the organization's existence or make its status unbalanced cannot be considered a crisis. It is incorrect to refer to common leadership issues that lead to low morale and motivation (getting the business and its leaders into difficulty, inability to collect accurate and comprehensive information, presence of communication issues, and differing employee expectations) as a crisis (Anwar \& Qadir, 2017).

While crises are often preceded by warning signs, they can also occur as a result of a series of unexpected occurrences. In this context, crises can be classified into two types: abrupt and ongoing crises (Anwar \& Shukur, 2015): These include the unexpected deterioration and imbalance of events that have a detrimental impact on employees, leaders, investors, consumers, suppliers, public opinion, organization revenues, and outcomes, all without prior notice to the firm's leaders. According to (Anwar \& Surarchith, 2015), crises can occasionally be caused by the organization's internal deficiencies. In other words, conditions such as organizational structure rigidity, communication breakdowns, and managerial incapacity can all be crisis factors. The shortcomings and flaws within leadership styles are a second key reason for the occurrence of leadership crises. Several internal variables in a leader's life might be identified as reasons that can lead to failure and even crises (Anwar, 2016).

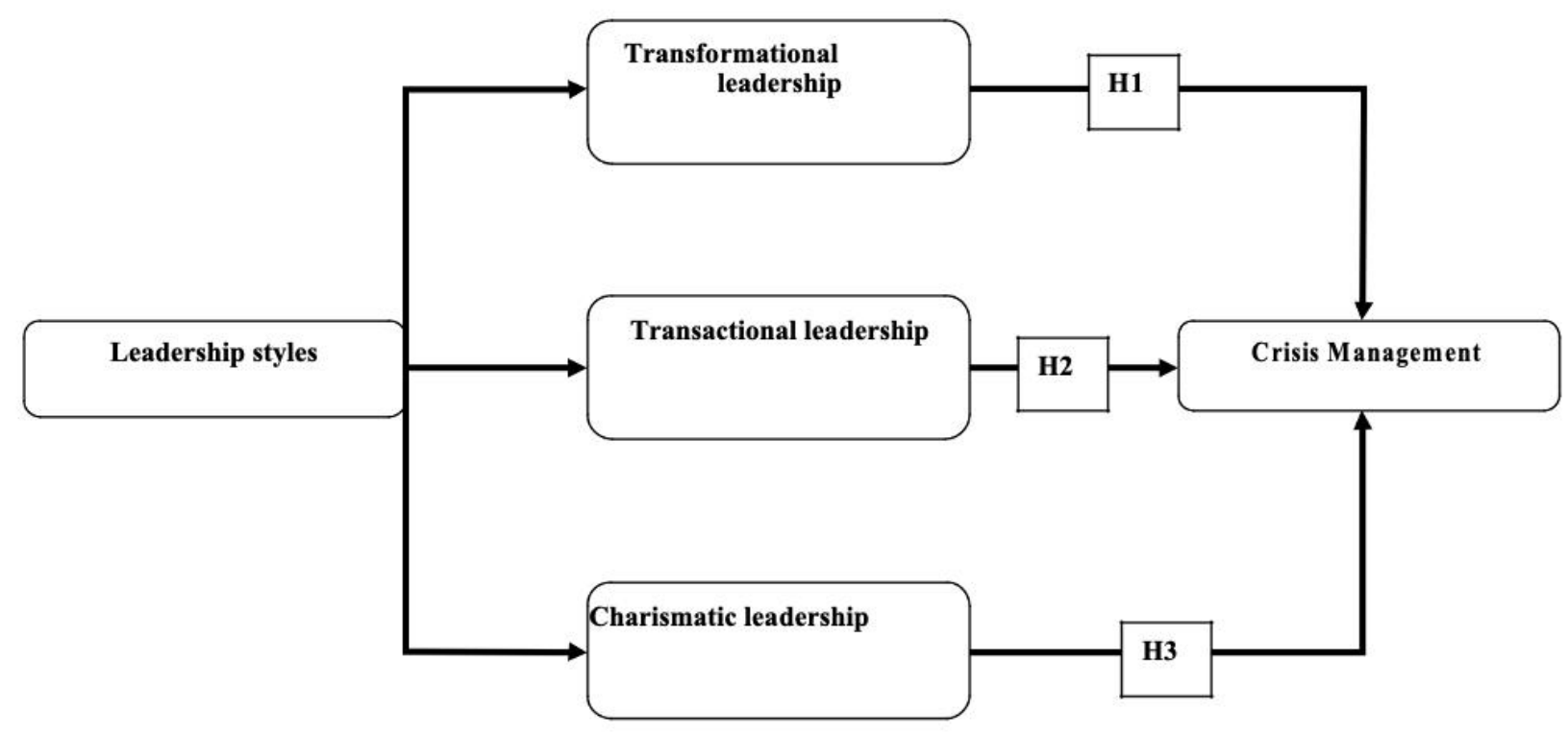

Fig.1: Conceptual framework

\section{Research Hypotheses}

H1: There is a significant affect of transformational leadership on Crisis management

H2: There is a significant affect of transactional leadership on Crisis management

H3: There is a significant affect of charismatic leadership on Crisis management

\section{METHODOLOGY}

\section{Research Design}

The researchers used a quantitative technique to test this study. A questionnaire used to collect necessary data. According to (Kumar, 2005) this study can be described as a cross-sectional study, based on the number of possible contacts out of the chosen study population. 


\section{Sampling}

A sample design is a plan for attaining certain sample from a provided population. Sample design refers to the procedure or method the researcher is willing to accept in choosing items for the sample. Sampling is "the process of selecting a few (a sample) from a bigger group (the sampling population) to become the basis for estimating or predicting the prevalence of an unknown piece of information. The research used random sampling method to find out the relationship between leadership styles and crisis management. Sampling elements therefore have to be representative for the main population. The mentioned random sampling was carried out in locations in the ministry of planning in Erbil. A total of 800 questionnaires were distributed in the ministry of planning, however 630 questionnaires were received and being completed properly and the data were collected through in hard copies.

\section{Questionnaire}

The researchers adopted questionnaire from earlier studies to test the current study. The questionnaire has been validated by earlier researchers to be ideal for measuring, the questionnaire modified from ( Gill, et al., 2011,Sadeghi and Pihie, 2012, Murphy \& Ensher,2008, Flynn\& Staw, 2004, Hinkin \& Tracey, 1999, Judge \& Piccolo,2004). The questionnaire consisted of two main sections; the first section included five personal information questions for each participant such as; age, gender, level of education and participante's position, the part two of the survey compromised of 102 items for all variables. The study is investigating the three leadership styles (transformational leadership, transactional leadership and charismatic leadership) as independent factor and crisis management as dependent factor. The participants were asked to rate how important each item are according to the five point ordered scales, ranging from $1=$ strongly disagree to $5=$ strongly agree.

\section{ANALYSIS AND FINDINGS}

The main aim of this research is to analyse the relationship between leadership styles and crisis management. As it mentioned previously total of 630 participants were involved in completing the questionnaire. The respondents were requested to rate how important they perceived each item on five point ordered scales. All data were analyzed by using SPSS version 20.

Table 1. Reliability Test

\begin{tabular}{lcc}
\hline Factor & Cronbach's Alpha & N of Items \\
\hline Transformational leadership & .76 & 37 \\
\hline Transactional leadership & & 26 \\
\hline Charismatic leadership & .66 & 28 \\
\hline Crisis management & .68 & \\
\hline
\end{tabular}

Table (1) presents the reliability test for three independent variables and a dependent The Alpha for transformational leadership styles $=.760>.6$ (Kothari, 2004) this means that 37 items used for transformational leadership style were reliable, The Alpha for transactional leadership styles $=.660$, this means that 26 items used for transactional leadership style were reliable. The Alpha for charismatic leadership styles $=.680$, this means that 28 items used for charismatic leadership style were reliable and the Alpha for crisis management $=.712$, this means that 30 items used for crisis management were reliable.

Table 2. Correlations Analysis

Factors $\quad$ Pearson Correlation Crisis Management

\begin{tabular}{lll}
\hline Transformational leadership & Pearson Correlation & $662^{* *}$
\end{tabular}


Sig. (2-Tailed)

$\overline{\mathrm{N}}$

Pearson Correlation

Sig. (2-Tailed)

.000

N 630

Charismatic leadership

Pearson Correlation

$629^{*}$

Sig. (2-Tailed)

.000
000

630
Transactional leadership

$526^{* * *}$

\begin{tabular}{ll}
\hline Sig. (2-Tailed) & .000 \\
\cline { 2 - 2 } & 630 \\
\hline
\end{tabular}

**. Correlation is significant at the 0.01 level (2-tailed).

Table (2) presents the correlations between three independent variable and dependent variable. It was found that transformational leadership style has significant correlation $\left(\mathrm{r}=.662^{* *}, \mathrm{p}<0.01\right)$ with crisis management. Concerning the strength of the linear relationship is moderate between transformational leadership and crisis management. Furthermore, transactional leadership style has significant correlation $\left(r=.526^{* *}, \mathrm{p}<0.01\right)$ with crisis management. Concerning the strength of the linear relationship is moderate between transactional leadership and crisis management and charismatic leadership style has significant correlation $\left(\mathrm{r}=.629^{* *}, \mathrm{p}<0.01\right)$ with crisis management. Concerning the strength of the linear relationship is moderate between charismatic leadership and crisis management.

Table 3: Coefficients

\begin{tabular}{lccc}
\hline Independent variable & Coefficients & t-value & P-value \\
\hline Charismatic leadership & .529 & 9.455 & .000 \\
\hline Transactional leadership & & & .000 \\
\hline Transformational leadership & .046 & 6.929 & .000
\end{tabular}

\begin{tabular}{lcc}
\hline $\mathrm{R} 2$ & .642 & \\
\hline F value & 374.202 & .000
\end{tabular}

Dependent Variable: Crisis Management

This article can be downloaded from here: www.ijaems.com
Table (3) present the findings of multiple regression analysis, it was found that charismatic leadership has significantly predicted crisis management (Beta is weight 
$0.529, \mathrm{p}<.001)$ this indicates that charismatic leadership will have a direct positive association with crisis management, transactional leadership has significantly predicted crisis management (Beta is weight $0.046, \mathrm{p}<.001$ ) this indicates that transactional leadership will have a direct positive but weak association with crisis management and transformational leadership has significantly predicted crisis management (Beta is weight 0.426, p<.001) this indicates that transformational leadership will have a direct positive but weak association with crisis management. Furthermore, it was found that the value of $\mathrm{R}$ square $=.64$ this indicates that $64 \%$ of total variation in crisis management has explained by the three styles of leadership (charismatic leadership, transformational leadership and transactional leadership), also the F value for the three styles of leadership (charismatic leadership, transformational leadership and transactional leadership) as independent variable $=374.202(374.202>1)$ this indicates there is a significant relation between three styles of leadership (charismatic leadership, transformational leadership and transactional leadership) and crisis management.

\section{DISCUSSION}

The highest value among all leadership styles was found to be charismatic leadership. (Bipath, 2012), discussed that leaderes vision characteristic ought to leave of personal style and try to make the most excellent to convince all to be member, and the leadership style mostly with leaderes vision characteristic will make appropriate strategies within timeframe. (Jong, et al., 2016), stated that leaderes vision characteristic) motivating and coaching employees could drive leaders to present carefully their leadership style. (Jordan, et al., 2016), argued that leader"s vision characteristic would have the role of tactician, which is, and management during crisis should to take the leader"s vision characteristic as the core. As for administration, leadership contents ought not to be restricted only to explaining different styles or caring staffs and productive effectiveness. (Lai, et al., 2016), presented that leaders should have the power of leaderes vision characteristic further to their leadership style if supposing to lead an organization during crisis to the maintainable operation and administration. Consequently, (Bipath, 2012), discussed that leaders should make vision as the core of the leadership style and get benefits of the communication and integration to efficiently execute the practice and management during crisis. At the time an organization experiences crisis, the way that charismatic leaders with personal risk characteristic deal with such crisis establishes new values, new norms, and exposes significant assumptions. Crises are particularly important in creating a culture and transmission because the reason is the emotional association during such eras raises the strength of learning. For instance, a firm faced bankrupt, the reason behind bankrupt is over engineered, also the firm`s products are so expensive. The firm tried to maintain by producing lower quality of products in order to be able to remain competitive in the market area. Later on the market area required high quality products based on customer`s demand, this firm was not able to produce better quality of the product to protect itself from bankrupt. Crises about matters of internal integration could also expose and embed the assumptions of leader. The best time to control an organization is when performances of insubordination took place. Thus much of the culture of an organization is based on hierarchy, power, authority, and power. For instance, Olsen visibly and frequently exposed his assumption that he didn ${ }^{\text {ee }} \mathrm{believe}$ that he recognized best based on his understanding and motivating behaviour when followers discussed with him.

Charismatic leader"s sensitivity to follower characteristic one of the most understated yet most powerful methods in which founder"s assumptions become embedded and continued is the practice of choosing new members. For instance, Olsen supposed that the best method to shape an organization was to employ very clever, tough, independent individual, articulate, and then assign them lots of responsibility. Another example by Ciba-Geigy employed very clever person who should be suitable into the culture that had developed over a century.

Previous studies supported the study is in line with about the national culture. Indonesia has a score of 46 lowto moderate masculinity. This suggests that low levels of encouragement to produce high performance or a strongorganizational culture. If the traditional culture is not formed into a powerful organizational culture that fit the global business environment, the organizational culture had no effect on organizational performance. This study is also consistent with the "dysfunctional culture, dysfunctional organization capturing the behavioural norms of organizational culture and drive performance". He found that a charismatic leader with sensitivity to followerees characteristic has significant effect on organizational culture improvement during crisis.

According to (Martin, 2015), Leaders ${ }^{\text {ee }}$ unconventional behaviour characteristic is the main aspect that defines the growth in organizational performance in crisis time, this type of characteristic arises from some group dynamics, the practice to affect others as well as a mechanism in accomplishing organizational goal in crisis time. When we usually go into an organization will be able to see the difference between each organization with various leaders. The phenomenon that we enter in an organization, 
for instance employee behaviours, team workers, integrity, and so on, all of those reflect the leadership and leaders of that organization. Organizational culture also is the main aspect for innovation, creativity, knowledge management, and leadership. Leaderse unconventional behaviour characteristics, in numerous researches have shown empirically and theoretically, as the main aspect enhancing performance of an organization. Organizational culture, based on Schein is the concept of creating on three levels: values, artefacts, and basic assumption, based on the symbols that apply. According to the viewpoint of organizational learning, Leaders ${ }^{\text {ee }}$ unconventional behaviour characteristic is the simple assumptions that have been created before, and as a direction of behaviour for individuals of the organization regarding of problems.

\section{CONCLUSIONS}

The rapid transformations experienced in economy and other external environment conditions and certain negativities present within the structure of the organization may drag the management into extraordinary situations named as " "crisis ${ }^{\text {eee }}$. When it is considered that the crisis is the situations that can be affected and even end the activities and presence of the organization, it is essential to take the necessary precautions accordingly. This study mainly discussed the relationship between the leadership style, the crisis management in the ministry of planning in Erbil, and also inspected whether interaction between certain leadership characteristic and crisis management. Research results showed that charismatic leadership has turn out to be rigorous in latest decades and that firms growth tactics usually request modifying during crisis time. Thus, an organization is more enthusiastic comparing with individual who is carrying the charisma and has ability to modify and transform firms ${ }^{\text {ee }}$ tactics and culture and facilitate the firm to be more flexible to exterior environmental needs at the time of crisis. The crisis is the chaotic situations that the organizations and the society can encounter and create chaos. On the other hand, there is not any method that can thoroughly prevent the possibility of crisis. When the crisis in question is a natural disaster, knowing this beforehand and foretelling the results is impossible at least for knowledge. The step to be taken to be prepared against crisis and the results to be created, to take necessary precautions to develop early warning systems and to get rid of the crisis with minimum damage by managing the chaotic situation created by the crisis. The other precautions utilized against crisis, on the other hand, were dismissal of personnel reduction of expenditures and ceasing of investments. However, certain organization went too far in such applications by disregarding the future. Certain other organization on the other hand, by regarding that the crisis is only temporary, have prepared themselves to their reanimation period without discontinuing investment. The most important issue to be mentioned regarding this subject is that the easiest way of getting rid of crisis is the necessity of taking the necessary precautions at the organization prior to the occurrence of crisis.

\section{IMPLICATIONS FOR FUTURE STUDIES}

According to the research findings mentioned previously, there is more to uncover on the subject of leadership styles and crisis management in the ministry of planning in Erbil. A bigger sample size and including all the key races in Erbil would provide support. The findings of this study will be beneficial for the field of culture studies for instance culture diversification and its relationship with leadership styles, moreover the researchers suggested further studies to be conducted in the field of cultural issues with the relationship with leadership styles to find out whether culture will have an effect of accepting certain leadership style.

\section{REFERENCES}

[1] Top, C., \& Ali, B. J. (2021). Customer satisfaction in online meeting platforms: Impact of efficiency, fulfillment, system availability, and privacy. Amazonia Investiga, 10(38), 7081. https://doi.org/10.34069/AI/2021.38.02.7

[2] Demir, A., Maroof, L., Sabbah Khan, N.U. and Ali, B.J. (2020), "The role of E-service quality in shaping online meeting platforms: a case study from higher education sector", Journal of Applied Research in Higher Education. https://doi.org/10.1108/JARHE-08-2020-0253

[3] Ali, B, J. (2021). Impact of consumer animosity, boycott participation, boycott motivation, and product judgment on purchase readiness or aversion of Kurdish consumers in Iraq. Journal of Consumers Affaires; 1-20. https://doi.org/10.1111/joca.12350

[4] Ali, B, J. (2020). Impact of COVID-19 on consumer buying behavior toward online shopping in Iraq. Economic studies journal. 18(42): 267-280. Retrieved from https://www.asjp.cerist.dz/en/article/134070

[5] Ali, B.J. (2021) Assessing (The impact) of advertisement on customer decision making: Evidence from an educational institution. Afak for sciences journal, 6(1): 425-439. Retrieved from https://www.asip.cerist.dz/en/article/141056

[6] Ali, B.J. (2021) Consumer attitudes towards healthy and organic food in the Kurdistan region of Iraq. Management Science Letters. 11: 1-8. DOI: 10.5267/j.msl.2021.2.015

[7] Andavar, V., Ali, B.J., and Ali, S.A. (2020) Rainwater for Water Scarcity Management: An Experience of Woldia University (Ethiopia). Journal of Business, Economics and Environmental Studies, 10-(4): 29-34. DOI: 10.13106/jbees.2020.vol10.no4.29

[8] Faraj, K. M., Faeq, D. K., Abdulla, D. F., Ali, B. J., \& Sadq, Z. M. (2021). Total Quality Management And Hotel 
Employee Creative Performance: The Mediation Role Of Job Embeddedment. Journal of Contemporary Issues in Business and Government, 27(1), 3838-3855. http://dx.doi.org/10.47750/cibg.2021.27.01.001

[9] Ali, B. J. (2016). Iraq Stock Market and its Role in the Economy. Retrieved from https://www.amazon.com/IraqStock-Market-Role-Economy/dp/3659634271

[10] Ali, B. J. (2014). Brand Building in the Consumer Electronics Industry in Iraq. Retrieved from https://www.amazon.com/Brand-Building-ConsumerElectronics-Industry/dp/6200248699

[11] Ali, B. J., \& Anwar, G. (2021). Factors Influencing the Citizens' Acceptance of Electronic Government. International Journal of Engineering, Business and Management, $\quad 5(1), \quad 48-60$. https://doi.org/10.22161/ijebm.5.1.5

[12] Saleh, P. F., Ali, B. J., Akoi, S., Najmalddin, B., Ali, R. S., \& Anwar, G. (2021). Factors affecting the Success of Female Entrepreneurs in Kurdistan. International journal of Engineering, Business and Management (IJEBM), 5.

[13] Ali, B. J., \& Anwar, G. (2021). The Effect of Marketing Culture Aspects of Healthcare Care on Marketing Creativity. International Journal of English Literature and Social Sciences, 6(2), 171-182. https://doi.org/10.22161/ijels.62.25

[14] Ali, B. J., \& Anwar, G. (2021). An Empirical Study of Employees' Motivation and its Influence Job Satisfaction. International Journal of Engineering, Business and Management, $\quad 5(2), \quad 21-30$ https://doi.org/10.22161/ijebm.5.2.3

[15] Ali, B. J., Saleh, P. F., Akoi, S., Abdulrahman, A. A., Muhamed, A. S., Noori, H. N., \& Anwar, G. (2021, May). Impact of Service Quality on the Customer Satisfaction: Case study at Online Meeting Platforms. In Ali, BJ, Saleh, Akoi, S., Abdulrahman, AA, Muhamed, AS, Noori, HN, Anwar, G.(2021). Impact of Service Quality on the Customer Satisfaction: Case study at Online Meeting Platforms. International journal of Engineering, Business and Management (Vol. 5, No. 2, pp. 65-77).

[16] Ali, B. J., \& Anwar, G. (2021). The balanced scorecard's evolution as a strategic mechanism at banking sectors. International Journal of English Literature and Social Sciences, $\quad 6(1), \quad 471-478$. https://doi.org/10.22161/ijels.61.63

[17] Anwar, G., \& Abdullah, N. N. (2021). Inspiring future entrepreneurs: The effect of experiential learning on the entrepreneurial intention at higher education. International Journal of English Literature and Social Sciences, 6.

[18] Ali, B. J., \& Anwar, G. (2021). Measuring competitive intelligence Network and its role on Business Performance. International Journal of English Literature and Social Sciences, 6(2), 329-345. https://dx.doi.org/10.22161/ijels.62.50

[19] Anwar, G., \& Abdullah, N. N. (2021). The impact of Human resource management practice on Organizational performance. International journal of Engineering, Business and Management (IJEBM), 5.
[20] Abdullah, N. N., \& Anwar, G. (2021). An Empirical Analysis of Natural Gas as an Alternative Fuel for Internal Transportation. International Journal of English Literature and Social Sciences, 6(1).

[21] Ali, B. J., \& Anwar, G. (2021). A study of knowledge management alignment with production management: A study of carpet manufacture in Kurdistan region of Iraq. International Journal of English Literature and Social Sciences, 6(2), 346-360. https://dx.doi.org/10.22161/ijels.62.51

[22] Ali, B. J., \& Anwar, G. (2021). The mediation role of change management in employee development. International Journal of English Literature and Social Sciences, 6(2), 361374. https://dx.doi.org/10.22161/ijels.62.52

[23] Anwar, K., \& Louis, R. (2017). Factors Affecting Students' Anxiety in Language Learning: A Study of Private Universities in Erbil, Kurdistan. International Journal of Social Sciences \& Educational Studies, 4(3), 160.

[24] Ali, B. J., \& Anwar, G. (2021). Business strategy: The influence of Strategic Competitiveness on competitive advantage. International Journal of Electrical, Electronics and Computers, 6(2), 1-10. https://dx.doi.org/10.22161/eec.62.1

[25] Anwar, K. (2017). Leading Construction Project Teams: The Effectiveness of Transformational Leadership in Dynamic Work Environments in Kurdistan. International Journal of Advanced Engineering, Management and Science, 3(10), 239925.

[26] Ali, B. J., \& Anwar, G. (2021). Strategic leadership effectiveness and its influence on organizational effectiveness. International Journal of Electrical, Electronics and Computers, 6(2), 11-24. https://dx.doi.org/10.22161/eec.62.2

[27] Anwar, K., \& Qadir, G. H. (2017). A Study of the Relationship between Work Engagement and Job Satisfaction in Private Companies in Kurdistan. International Journal of Advanced Engineering, Management and Science, 3(12), 239944.

[28] Ali, B. J., \& Anwar, G. (2021). Intellectual capital: A modern model to measure the value creation in a business. International journal of Engineering, Business and Management, 5(2), 31-43. https://dx.doi.org/10.22161/ijebm.5.2.4

[29] Ali, B. J., \& Anwar, G. (2021). Marketing Strategy: Pricing strategies and its influence on consumer purchasing decision. International journal of Rural Development, Environment and Health Research, 5(2), 26-39. https://dx.doi.org/10.22161/ijreh.5.2.4

[30] Anwar, K. (2017). Factors Affecting Stock Exchange Investment In Kurdistan. The International Journal of Accounting and Business Society, 25(1), 32-37.

[31] Ali, B. J., \& Anwar, G. (2021). Organization citizenship behaviour as a determining Factor in Business outcome. International journal of Rural Development, Environment and Health Research, 5(2), 17-25. https://dx.doi.org/10.22161/ijreh.5.2.3

[32] Anwar, K., \& Climis, R. (2017). Analyzing the relationship between types of advertisement and customer choice: a study 
of retailer stores in erbil. The International Journal of Accounting and Business Society, 25(2), 43-52.

[33] Talim, S.R., Ali, B.J., Top, C. (2021). Elaborating the Antecedents of Purchase Intentions in Second-Hand Car Industry: Case Study in Kurdistan Region of Iraq. Journal of Contemporary Issues in Business and Government, 27(3), 1526-1547. http://dx.doi.org/10.47750/cibg.2021.27.03.204

[34] Anwar, K., \& Ghafoor, C. (2017). Knowledge management and organizational performance: A study of private universities in Kurdistan. International Journal of Social Sciences \& Educational Studies, 4(2), 53.

[35] Ali, B. J., Saleh, Akoi, S., Abdulrahman, A. A., Muhamed, A. S., Noori, H. N., Anwar, G. (2021). Impact of Service Quality on the Customer Satisfaction: Case study at Online Meeting Platforms. International journal of Engineering, Business and Management, 5(2), 65-77. https://dx.doi.org/10.22161/ijebm.5.2.6

[36] Hameed, A. A., \& Anwar, K. (2018). Analyzing the Relationship between Intellectual Capital and Organizational Performance: A Study of Selected Private Banks in Kurdistan. International Journal of Social Sciences \& Educational Studies, 4(4), 39.

[37] Jamal Ali, B., Akoi, S., Fadel Saleh, P., \& Sardar, zhilwan. (2021). Factors Shaping Customer Satisfaction with Residential Flats: Evidence from Sulaymaniyah City. Black Sea Journal of Management and Marketing, 2(2), 1-12. https://doi.org/10.47299/bsjmm.v2i2.69

[38] Akoi, S., Jamal Ali, B., Fadel Saleh, P., Najmalddin, B., Sabah Mustafa, R., Rzgar Abdulmajid, M., \& Rebwar Hama, A. (2021). Elaborating the Characteristics that Affect Buyers in Online Shopping: The Case of Generation Z Girls in Kurdistan Region of Iraq. Black Sea Journal of Management $\begin{array}{lllll}\text { and } & \text { Marketing, } & 2(2), & 42 & -\end{array}$ https://doi.org/10.47299/bsjmm.v2i2.74

[39] Anwar, K. (2017). The Role of Effective Leadership in Crisis Management: Study of Private Companies in Kurdistan. Qalaai Zanist Scientific Journal, 2(4), 326-338.

[40] Ahmed, S. Y., Ali, B. J., Top, C. (2021). Understanding the Impact of Trust, Perceived Risk, and Perceived Technology on the Online Shopping Intentions: Case Study in Kurdistan Region of Iraq. Journal of Contemporary Issues in Business and Government, 27(3), 2136-2153. http://dx.doi.org/10.47750/cibg.2021.27.03.264

[41] Anwar, K., \& Balcioglu, H. (2016). The relationship between transformational leadership characteristics and effectiveness: A case study of construction companies in Erbil. International Journal of Science Technology and Management, 5(2), 250-256.

[42] Sabir, B. Y., Othman, B .J., Gardi, B., Ismael, N. B., Hamza, P. A., Sorguli, S., Aziz, H. M., Ahmed, S. A., Ali, B. J., Anwar, G. (2021). Administrative Decentralization: The Transfer of Competency from The Ministry of Education to General Directorates. International Journal of Rural Development, Environment and Health Research, 5(3), 113. https://doi.org/10.22161/ijreh.5.3.1

[43] Abdullah, M. S., Toycan, M., \& Anwar, K. (2017). The cost readiness of implementing e-learning. CUSTOS E AGRONEGOCIO ON LINE, 13(2), 156-175.
[44] Ali, B. J., Anwar, G., Gardi, B., Othman, B. J., Aziz, H. M., Ahmed, S. A., Hamza, P. A., Ismael, N. B., Sorguli, S., Sabir, B. Y. (2021). Business Communication Strategies: Analysis of Internal Communication Processes. Journal of Humanities and Education Development, 3(3), 16-38. https://doi.org/10.22161/jhed.3.3.4

[45] Anwar, K. (2016). Comparison between cost leadership and differentiation strategy in agricultural businesses. Custos E Agronegocio on Line, 12(2), 212-231.

[46] Ali, B. J., Gardi, B., Othman, B. J., Ismael, N. B., Sorguli, S., Sabir, B. Y., Ahmed, S. A., Hamza, P. A., Aziz, H. M., Anwar, G. (2021). Educational system: The policy of Educational system in Kurdistan Region in public Kindergarten. International Journal of English Literature and Social Sciences, 6(3), 062-071. https://doi.org/10.22161/ijels.63.10

[47] Anwar, K. (2017). Analyzing the conceptual model of service quality and its relationship with guests'satisfaction: a study of hotels in erbil. The International Journal of Accounting and Business Society, 25(2), 1-16.

[48] Aziz, H. M., Othman, B. J., Gardi, B., Ahmed, S. A., Sabir, B. Y., Ismael, N. B., Hamza, P. A., Sorguli, S., Ali, B. J., Anwar, G. (2021). Employee Commitment: The Relationship between Employee Commitment And Job Satisfaction. Journal of Humanities and Education Development, 3(3), 54-66. https://doi.org/10.22161/jhed.3.3.6

[49] Anwar, G., \& Shukur, I. (2015). The Impact of Service Quality Dimensions on Students' Satisfaction. International Journal of Social Sciences \& Educational Studies, 76.

[50] Ali, B. J., Gardi, B., Othman, B. J., Ahmed, S. A., Ismael, N. B., Hamza, P. A., Aziz, H. M., Sabir, B. Y., Anwar, G. (2021). Hotel Service Quality: The Impact of Service Quality on Customer Satisfaction in Hospitality. International Journal of Engineering, Business and Management, 5(3), 14-28. https://doi.org/10.22161/ijebm.5.3.2

[51] Anwar, G., \& Surarchith, N. K. (2015). Factors Affecting Shoppers' Behavior in Erbil, Kurdistan-Iraq. International Journal of Social Sciences \& Educational Studies, 1(4), 10.

[52] Sorguli, S., Gardi, B., Othman, B.J., Aziz, H. M., Ahmed, S. A., Sabir, B. Y., Ismael, N. B., Hamza, P. A., Ali, B. J., Anwar, G. (2021) Innovation: Knowledge Management in the Innovating Industries, 6(3), 10-23. https://dx.doi.org/10.22161/eec.63.2

[53] Anwar, G., \& Abd Zebari, B. (2015). The Relationship between Employee Engagement and Corporate Social Responsibility: A Case Study of Car Dealership in Erbil, Kurdistan. International Journal of Social Sciences \& Educational Studies, 2(2), 45.

[54] Hamza, P. A., Othman, B. J., Gardi, B., Sorguli, S., Aziz, H. M., Ahmed, S. A., Sabir, B. Y., Ismael, N. B., Ali, B. J., Anwar, G. (2021). Recruitment and Selection: The Relationship between Recruitment and Selection with Organizational Performance. International Journal of Engineering, Business and Management, 5(3), 1-13. https://doi.org/10.22161/ijebm.5.3.1 
[55] Anwar, G., \& Shukur, I. (2015). the impact of recruitment and selection on job satisfaction: Evidence from private school in Erbil. International Journal of Social Sciences \& Educational Studies, 1(3), 4-13.

[56] Ali, B. J., Gardi, B., Othman, B. J., Sabir, B. Y., Sorguli, S., Ismael, N. B., Hamza, P.A., Aziz, H. M., Ahmed, A. A., Anwar, G. (2021). The Role of Shopping Malls on Kurdistan Regional Government's Economy. Journal of Humanities and Education Development, 3(3), 39-53. https://doi.org/10.22161/jhed.3.3.5

[57] Anwar, G., \& Shukur, I. (2015). Job satisfaction and employee turnover intention: A case study of private hospital in Erbil. International Journal of Social Sciences \& Educational Studies, 2(1), 73.

[58] Ahmed, S. A., Othman, B. J., Gardi, B., Sabir, B. Y., Ismael, N. B., Hamza, P. A., Sorguli, S., Aziz, H. M., Ali, B. J., Anwar, G. (2021). Students' Attitudes towards Learning English in the Kurdistan region of Iraq. International Journal of English Literature and Social Sciences, 6(3), 072-087. https://doi.org/10.22161/ijels.63.11

[59] Anwar, G., \& Shukur, I. (2015). The Impact of Training and Development on Job Satisfaction: A Case Study of Private Banks in Erbil. International Journal of Social Sciences \& Educational Studies, 2(1), 65.

[60] Ismael, N. B., Othman, B. J., Gardi, B., Hamza, P. A., Sorguli, S., Aziz, H. M., Ahmed, S. A., Sabir, B. Y., Ali, B. J., Anwar, G. (2021). The Role of Training and Development on Organizational effectiveness. International Journal of Engineering, Business and Management, 5(3), 15-24. https://doi.org/10.22161/ijebm.5.3.3 